\begin{tabular}{c} 
JURNAL SAINS dan INOVASI PERIKANAN \\
Journal of Fishery Science and Innovation \\
e-ISSN:2502-3276 \\
Vol. 2, No.1,15-19, Januari 2018 \\
http://ojs.uho.ac.id/index.php/JSIPi \\
\hline
\end{tabular}

\title{
Keanekaragaman Juvenil Karang Batu (Ordo Scleractinia) di Perairan Sulawesi Tenggara Indonesia
}

\author{
Diversity of Scleractinian Corals Juvenile (Ordo Scleractiania) \\ In Southeast Sulawesi Waters Indonesia
}

\author{
Ratna Diyah Palupi ${ }^{\left.1)^{*}\right)}$, Rahmadani ${ }^{2)}$ \\ 1) Program Studi Oceanografi Fakultas Perikanan dan Ilmu Kelautan Universitas Halu Oleo,Kendari, Indonesia \\ ${ }^{2)}$ Program Studi Ilmu Kelautan Fakultas Perikanan dan Ilmu Kelautan Universitas HaluOleo, Kendari, Indonesia \\ Corresponding author ${ }^{*}$ : ratna_dp@uho.ac.id
}

\begin{abstract}
Scleractinia Coral juvenile diversity or abundance can be used to assess the recovery or regeneration of coral reefs ecosystem. Corals juvenile will grow up into mature eventually play an important role in the productivity of coastal waters. The study aim is to access the diversity of coral juvenile corals (family and genera) in the waters of Southeast Sulawesi. The methods used to inventory Coral juvenile is quadratic transect $1 \times 1 \mathrm{~m}$. Measurements performed on juvenile coral reef chicks having a diameter $\leq 5 \mathrm{~cm}$ long. Results showed that coral genera of Fungia, Pavona, Favia and Porites has contributed greatly to the diversity of juvenile corals to the whole location. The inventory of the number of juvenile corals found there were 234 species consisted of 21 genera and 12 families Sclerectinian corals. Tukalanggara patch reef and Bahulu Island had significantly higher of coral diversity than those in other locations.
\end{abstract}

Keywords : Abudance, Coral juvenile, Diversity, Southeast Sulawesi Waters

\begin{abstract}
ABSTRAK
Keberadaan juvenil karang merupakan indikasi tingkat pemulihan dan resiliensi dari ekosistem terumbu karang. Juvenil karang yang berhasil menjadi karang dewasa akan berperan penting terhadap produktivitas di perairan pesisir. Penelitian ini bertujuan untuk mengetahui keanekaragaman juvenil karang batu (Scleractinia) di Perairan Sulawesi Tenggara. Inventarisasi juvenil karang menggunakan transek kuadrat $1 \mathrm{~m}^{2}(1 \mathrm{x} 1 \mathrm{~m})$. Fokus obyek pengamatan pada anakan karang yang berdiameter $\leq 5 \mathrm{~cm}$. Hasil penelitian menunjukkan bahwa jumlah juvenil karang tercatat selama penelitian sebanyak 234 anakan karang yang masuk dalam 21 genera dan 12 famili. Dari data tersebut tercatat genus Fungia, Pavona, Favia, dan Porites mempunyai kontribusi besar terhadap keanekaragam juvenil karang di lokasi penelitian. Keanekaragaman juvenil karang tertinggi tercatat di sekitar gosong karang Tukalanggara dan Pulau Bahulu
\end{abstract}

Kata kunci : Juvenil karang, Keanekaragaman, Kelimpahan, Perairan Sulawesi Tenggara

DOI: http://dx.doi.org/10.33772/jspi. 
16 Ratna D.Palupi dan Rahmadani

JURNAL SAINS dan INOVASI PERIKANAN/ Journal of Fishery Science and Innovation

Vol. 2, No. 1, 15-19, Januari 2018

\section{PENDAHULUAN}

Perairan Sulawesi Tenggara menyimpan potensi sumber daya terumbu karang yang besar. Sebagai bagian dari segitiga karang dunia atau Coral Triangle Initiative (CTI), keanekaragaman karang di wilayah ini haruslah dapat diinventarisasi dengan baik sehingga nantinya dapat dilakukan pengelolaan secara benar dan terarah. Hasil penelitian Siringoringo et al., (2012) menyebutkan bahwa keanekaragaman karang dewasa di Perairan Kendari ditemukan sebanyak 184 jenis karang Scleractinia yang masuk dalam 15 famili. Potensi sumber daya karang ini haruslah dapat dikelola dengan baik untuk menyokong potensi sumber daya perikanan dan kelautan khususnya di perairan Sulawesi Tenggara.

Keberadaan juvenil karang atau anakan karang di suatu perairan dapat menjadi peran penting untuk mengetahui potensi sumber daya karang. Informasi mengenai potensi dan keanekaragaman juvenil karang dapat digunakan sebagai patokan tingkat pemulihan maupun kesuksesan komunitas terumbu karang disuatu perairan. Kesuksesan planula karang baik dalam masa planktonik maupun sesudah penempelan karang sangat mempengaruhi kelimpahan dan distribusi karang pada suatu daerah (Penin et al., 2007). Perhitungan rekruitmen karang sangat sulit dilakukan karena keberadaan juvenil karang sangat bergantung dari fase larva plantonik karang yang sangat sukar untuk diketahui asalnya.

Penelitian ini bertujuan untuk mengetahui keanekaragaman juvenil karang di lokasi penelitian. Hasil dari penelitian ini selanjutnya dapat digunakan untuk mengetahui potensi keanekaragaman terumbu karang dan tingkat regenerasi karang di perairan Sulawesi Tenggara khususnya di lokasi penelitian.

\section{METODE PENELITIAN}

Penelitian dilakukan pada bulan Juli 2011. Lokasi penelitian berada di sekitar Perairan Sulawesi Tenggara tepatnya di Teluk Wawobatu, Gosong karang Tukalanggara, Tanjung Tukalanggara, Pulau Bahulu, dan Pulau Labengke.

Data yang diambil terdiri dari data utama berupa keanekaragaman jenis juvenil karang. Data penunjang terdiri dari pengamatan terhadap topografi bawah laut, substrat dasar, dan kecerahan perairan sebagai data pendukung. Secara umum rata-rata kedalaman perairan pada saat pengambilan data di lokasi penelitian berkisar 6-7 meter. Pengambilan data karang dilakukan pada daerah slope atau lereng terumbu dengan kemiringan bervariasi antara $50-180^{\circ}$.

Metode pengamatan juvenil karang dilakukan dengan menggunakan transek kuadrat $1 \times 1 \mathrm{~m}$ atau dengan luas transek $1 \mathrm{~m}^{2}$ yang dikombinasikan dengan transek garis (Rogers et al., 2003; Penin et al., 2007). Dalam satu stasiun pengamatan dibuat 3 transek garis masing-masing dengan panjang $10 \mathrm{~m}$ yang diletakkan ditempat berbeda. Selanjutnya dalam satu garis transek diletakkan transek kuadrat pada meter pertama, kelima, dan terakhir, sehingga jumlah transek kuadrat dalam satu titik stasiun penelitian berjumlah sembilan transek (Bachtiar et al., 2012).

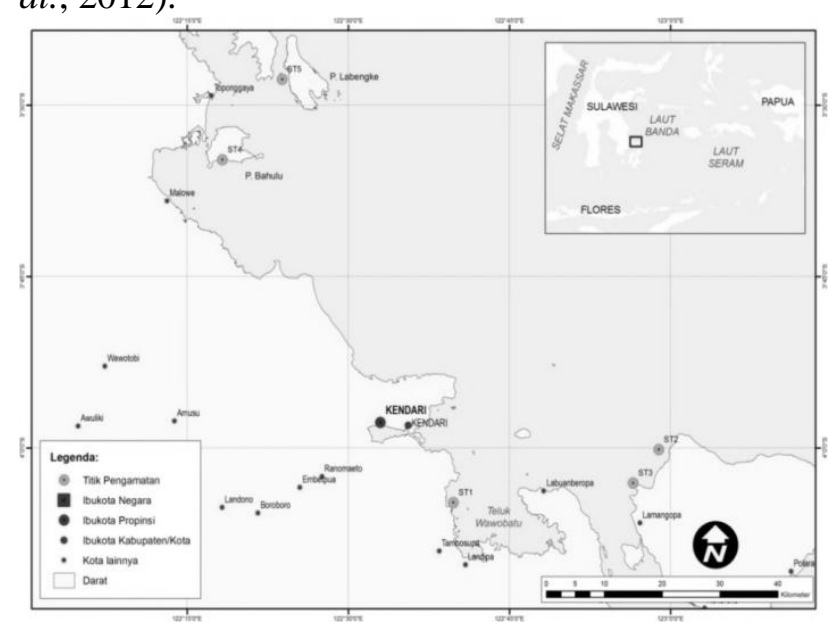

Gambar 1. Peta lokasi penelitian

Pengambilan data juvenil karang dilakukan secara langsung (in situ) dengan menggunakan alat bantu selam (scuba diving). Identifikasi juvenil karang dilakukan dengan cara menghitung dan mencatat semua jenis karang yang diameter panjangnya maksimal $5 \mathrm{~cm}(\leq 50 \mathrm{~mm})$ pada tiaptiap transek (Penin et al., 2007). Panjang diameter karang tersebut merupakan patokan ukuran karang yang masih muda (juvenil) atau kurang lebih karang tersebut berumur 3 tahun (Rogers et al., 2003; Penin et al., 2007). Semua karang yang masuk dalam kategori juvenil dicatat sampai tingkat genus dan tingkat spesies jika memungkinkan untuk selanjutnya dianalisa. 


\section{HASIL DAN PEMBAHASAN}

Hasil

Secara umum keanekaragaman juvenil karang di semua lokasi penelitian ditemukan sebanyak 234 juvenil yang masuk dalam 21 genera dan 12 famili karang batu Scleractinia (Gambar 2 dan 3). Distribusi juvenil karang berdasarkan lima lokasi penelitian menunjukkan hasil bahwa stasiun $\mathrm{P}$. Bahulu dan gosong karang Tukalanggaran mempunyai jumlah juvenil karang lebih tinggi dan lebih beragam dibanding ketiga stasiun lainnya, sedangkan $\quad P$. Labengke mempunyai keanekaragaman juvenil karang yang paling rendang dari semua lokasi penelitian (Tabel 1). Distribusi juvenil karang berdasarkan genera di stasiun Tukalanggara (gosong) hampir merata yaitu dari genus Euphylia, Favia, Fungia, Galaxea, Pavona, dan Porites. Kondisi tersebut berbeda dengan stasiun P. Bahulu, juvenil karang di lokasi ini didominasi oleh karang genus Fungia (karang jamur).

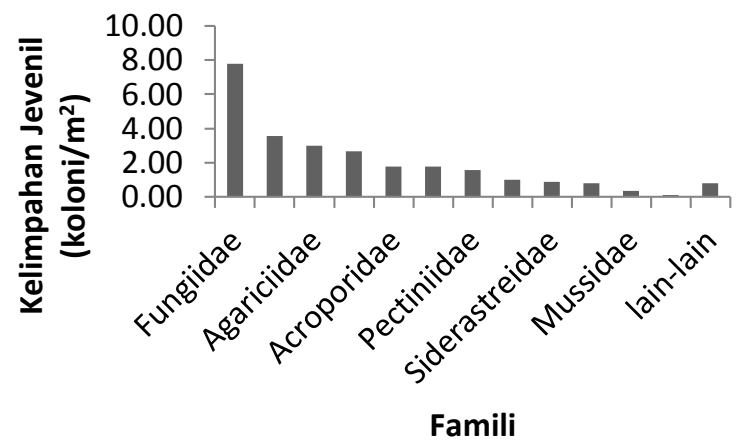

Gambar 2. Kelimpahan juvenil karang berdasarkan famili di Perairan Sulawesi Tenggara.

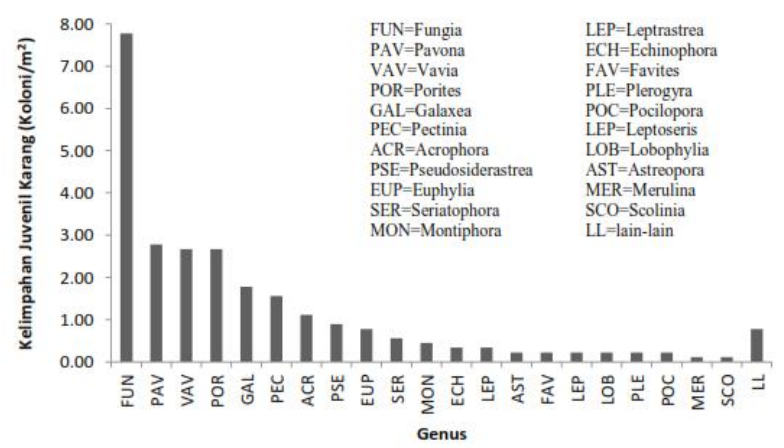

Gambar 3. Kelimpahan juvenil karang berdasarkan genus di Perairan Sulawesi Tenggara
Tabel 1. Jumlah koloni, Genus, dan Famili juvenil karang berdasarkan stasiun penelitian

\begin{tabular}{lccc}
\hline \multicolumn{1}{c}{ Stasiun } & $\begin{array}{l}\text { Jumlah } \\
\text { Koloni } \\
\text { Juvenil } \\
\text { Karang }\end{array}$ & $\begin{array}{c}\text { Jumlah } \\
\text { Genus }\end{array}$ & $\begin{array}{c}\text { Jumlah } \\
\text { Famili }\end{array}$ \\
\hline $\begin{array}{l}\text { Teluk Wawobatu } \\
\text { Tukalanggara } \\
\text { (gosong) }\end{array}$ & 36 & 12 & 9 \\
$\begin{array}{l}\text { Tukalanggara } \\
\text { (tanjung) }\end{array}$ & 68 & 13 & 9 \\
$\begin{array}{l}\text { Pulau Bahulu } \\
\text { Pulau Labengke }\end{array}$ & 35 & 11 & 9 \\
\hline
\end{tabular}

Topografi dasar laut pada tiap lokasi stasiun berbeda-beda yaitu dengan kemiringan pada daerah slope $50-180^{\circ}$ dengan kedalam 6-7 m. Berdasarkan pengamatan di lapangan didapatkan hasil substrat dasar di lokasi penelitian secara umum berupa pasir hingga pasir berlumpur dengan adanya stratifikasi kedalaman. Kondisi tersebut diduga karena pengaruh penebangan hutan dari lahan atas dan akibat aktivitas penambangan nikel disekitar lokasi penelitian. Hal tersebut diperkuat dengan selama pengambilan sampel, beberapa kali peneliti melihat kapal tongkang yang membawa muatan pasir yang mengandung nikel dan di dekat titik pengambilan sampel kondisi hutannya sudah rusak akibat penebangan hutan.

\section{Pembahasan}

Berdasarkan taxa, di lokasi penelitian ditemukan jumlah famili dan genus dari juvenil karang sebesar 21 genera dan 12 famili. Jumlah tersebut masih lebih tinggi jika dibandingkan dengan penelitian juvenil karang yang terdapat di gugus Pulau Pari Kepulauan Seribu (15 genera dan 10 famili) (Abrar, 2011), serta lebih rendah jika dibandingkan dengan juvenil karang di Perairan Pulau Lembata dan sekitarnya (30 genera dan 13 famili) (Bachtiar et al., 2012). Faktor letak topografi Perairan Sulawesi Tenggara yang masuk dalam kawasan segitiga karang dunia merupakan alasan tingginya keanekaragaman karang di lokasi penelitian jika dibandingkan dengan juvenil karang di Kepulauan Seribu. Keanekaragaman juvenil karang menunjukkan hasil famili Fungiidae merupakan karang yang paling dominan dengan kelimpahan sebesar $7.78 \mathrm{koloni} / \mathrm{m}^{2}$. Selanjutnya tiga famili yang mempunyai kelimpahan di atas 2.50 
18 Ratna D.Palupi dan Rahmadani

JURNAL SAINS dan INOVASI PERIKANAN/ Journal of Fishery Science and Innovation

Vol. 2, No. 1, 15-19, Januari 2018

koloni $/ \mathrm{m}^{2}$ adalah famili Faviidae $\left(3.56 \mathrm{koloni} / \mathrm{m}^{2}\right)$, Agariciidae (3.00 koloni $\left./ \mathrm{m}^{2}\right)$, dan Poritiidae (2.67 koloni/ $\left.\mathrm{m}^{2}\right)$ (Gambar 2).

Kelimpahan tertinggi juvenil karang di lokasi penelitian pada tingkat genus diperoleh dari genus Fungia dengan nilai kelimpahan sebesar 7.78 koloni $/ \mathrm{m}^{2}$ kemudian berturut-turut dari genus Pavona, Vavia, dan Porites dengan nilai kelimpahan sekitar $2.50 \mathrm{koloni} / \mathrm{m}^{2}$ (Gambar 3). Jika dilihat dari nilai tersebut nampak kelimpahan karang Fungia sangat dominan dibanding dengan genus lainnya, yaitu sekitar tiga kali lipat dari genus Pavona, Vavia, dan Porites. Hasil penelitian ini hampir sama dengan penelitian yang dilakukan oleh Crabbe and Smith (2003) di perairan Wakatobi Sulawesi Tenggara dimana genus Porites spp., Favites, dan Vavia spp. ditemukan dominan di perairan tersebut. Karang Fungia dikenal dengan sebutan karang jamur atau coral mushroom. Jenis karang ini merupakan kelompok karang yang hidup soliter atau sendiri-sendiri. Sifatnya yang soliter dan bisa bergerak walaupun sangat minim membuat juvenil karang ini dapat mencari habitat hidup yang cocok untuk tumbuh dan berkembang (Nugraha et al., 2004).

Jika dilihat dari keanekaragaman juvenil karang berdasarkan stasiun penelitian, Pulau Bahulu dan gosong karang Tukalanggara mempunyai kekayaan jumlah koloni, jumlah Genus, dan jumlah Famili yang tinggi dibanding ketiga stasiun penelitian lainnya (Tabel 1). Tingginya keanekaragaman juvenil karang di P. Bahulu dikarenakan faktor kondisi hidro-oseanografi yang menunjang pertumbuhan karang. Adanya pasokan nutrien berupa material organik dari limpasan sungai yang mengalir di area ini dapat memaksimalkan pertumbuhan karang khususnya juvenil karang. Distribusi juvenil karang yang ditemukan di P. Bahalu banyak terdapat di daerah slope dengan kedalaman $7 \mathrm{~m}$, dimana pengaruh air tawar dan sedimentasi sudah tidak berpengaruh lagi. Hal ini diperkuat dengan kondisi tutupan karang dewasa di tempat yang sama mencapai $68,73 \%$ atau dalam kondisi baik (Siringoringo et al., 2012). Tersedianya nutrien yang cukup di lokasi penelitian membuat biota karang tumbuh subur dan berkembang secara optimum. Selain itu tidak adanya kompetisi makanan dan kompetisi ruang antara karang dewasa dan juvenil karang di perairan tersebut membuat kondisi ekosistem di perairan ini dapat berjalan dengan stabil.

Hal berbeda terjadi pada juvenil karang di sekitar gosong karang Tukalanggara. Keanekaragaman juvenil karang lebih dipengaruhi oleh karakteristik habitat terumbu karang. Berdasarkan penelitian Siringoringo et al.( 2012), tutupan karang dewasa di sekitar perairan Tukalanggara mencapai $42.90 \%$ atau dalam kategori sedang. Hal ini berarti besar peluang bagi juvenil karang untuk melakukan rekruitmen di sekitar perairan tersebut. Rendahnya tutupan karang dewasa dapat memberikan kesempatan bagi juvenil karang untuk dapat berkembang (Bachtiar et al., 2012). Tidak adanya kompetisi ruang antara karang dewasa dan juvenil karang memungkinkan juvenil karang dapat berkembang secara maksimal di perairan Tukalanggara. Juvenil karang di lokasi ini mampu hidup dan bertahan baik itu untuk mendapatkan ruang maupun untuk mendapatkan makanan. Selain itu adanya subtrat dasar berupa pecahan karang (ruble) dan algae Halimeda dapat digunakan sebagai tempat penempelan planula karang untuk tumbuh dan menjadi karang dewasa dan dapat juga sebagai penghalang karang dewasa untuk dapat berkembang (Norstrom et al., 2007; Vermeij et al., 2009). Pecahan karang dan alga Halimeda atau disebut juga calcareus algae dimana kedua subtrat tersebut mengandung kalsium karbonat merupakan subtrat yang cocok bagi penempelan planula karang. Sebelum menjadi juvenil karang dan menetap di suatu subtrat, hasil fertilisasi karang dewasa akan bersifat plantonik. Larva karang tersebut akan mengembara sampai akhirnya menemukan substrat yang cocok sebagai media penempelan untuk selanjutnya menjadi polyp karang dan berkembang menjadi anakan karang (Munasik \& Widjatmoko, 2004).

Hal sebaliknya terjadi pada P. Labengke. Kekayaan juvenil karang di pulau tersebut menunjukkan hasil paling rendah diantara semua lokasi penelitian (Tabel 1). Rendahnya keanekaragaman juvenil karang di lokasi tersebut dikarenakan intensifnya aktifitas penambangan nikel dan penebangan hutan yang ada disekitar area pengambilan data. Salah satu akibat dari kegiatan tersebut adalah sedimentasi di sekitar perairan yang dapat menurunkan kualitas perairan. Kondisi tersebut diperparah dengan bentuk topografi pulau tersebut yang landai. Terumbu karang di lokasi ini 
ditemukan pada kedalaman 3-4 m sehingga pengaruh sedimentasi masih dirasakan oleh biota karang. Selama pengambilan data di lapangan beberapa kali peneliti menemui kapal tongkang mengangkut material tanah yang mengandung nikel baik itu pada saat sandar maupun melewati perairan P. Labengke. Crabbe and Smith (2003) ; International Society for Reef Studies (2004) menyatakan bahwa penambangan nikel dan penebangan hutan salah satunya dapat menyebabkan sedimentasi yang secara langsung dapat mengganggu aktivitas fertilisasi karang dewasa dan pertumbuhan juvenil karang. Partikel sedimen juga dapat menghambat polyp karang untuk mendapatkan makanan dan menghambat zooxanthellae dalam melangsungkan fotosintesis

\section{KESIMPULAN}

Keanekaragaman juvenil karang yang ditemukan di perairan Sulawesi Tenggara terdiri dari 234 juvenil yang masuk dalam 21 genera dan 12 famili karang batu Scleractinia. Dari lima lokasi penelitian, juvenil karang dengan kelimpahan tinggi terdapat di lokasi gosong karang Tukalanggara dan Pulau Bahulu. Genus yang dominan ditemukan di lokasi penelitian adalah genus Fungia dari famili Fungidae.

Ucapan terima kasih : Penulis mengucapkan terima kasih kepada rekan Tim Karang Ricoh M. Siringoringodan Tri Aryono Hadi. Kepada DIKTI yang mendanai Ekpedisi Perairan Kendari yang merupakan salah satu kegiatan join riset DIKTILIPI.

\section{DAFTAR PUSTAKA}

Abrar M. 2011. Kelulusan hidup rekruitmen karang (Scleractinia) di perairan gugus Pulau Pari, Kepulauan Seribu, Jakarta. Tesis. http://repository.ipb.ac.id/handle/ 123456789/46676. [5 Desember 2011].

Bachtiar I, Abrar M, Budiyanto A. 2012. Rekruitmen karang Scleractinia di Perairan Pulau Lembata. Ilmu Kelautan 17(1) : 1-7.

Crabbe MJ, Smith DJ. 2003. Computer modelling and estimation of recruitment patterns of nonbranching coral colonies at three sites in the Wakatobi Marine Park, S.E. Sulawesi, Indonesia; implications for coral reef conservation. Computational Biology and Chemistry. 27 : 17-27.

Dinas Perikanan dan Kelautan Provinsi Sulawesi Tenggara, 2003. Profil peluang investasi dan usaha kelautan dan perikanan Provisi Sulawesi Tenggara. Kendari.

Humphrey C, Weber M, Lott C, Cooper T, Fabricius K. 2008. Evects of suspended sediments, dissolved inorganic nutrients and salinity on fertilisation and embryo development in the coral Acropora millepora (Ehrenberg, 1834). Coral Reefs 27 : 837-850.

International Society for Reef Studies (ISRS). 2004. The effec of terrestrial runoff of sedimens, nutrient and other pollutions on coral reefs. Briefing paper 3, International Society for Reef Studies. 18p.

Munasik, Widjatmoko W. 2004. Reproduksi karang Acropora aspera di Pulau Panjang, Jawa Tengah: I. Gametogenesis. Indonesian Journal of Marine Sciences 9(4): 211-216.

Nugraha WA, Munasik, Widjatmoko W. 2004. Distribusi dan struktur populasi karang soliter Fungia fungites di Pulau Burung, Pulau Cemara Kecil dan Pulau Menjangan Kecil (Kepulauan Karimunjawa). Ilmu Kelautan 9(3) : 174-179.

Norstrom AV, Lokrantz J, Nyström M, Yap HT. 2007. Influence of dead coral substrate morphology on patterns of juvenile coral distribution. Marine Biology 150:7

Penin L, Adjeroud M, Pratchett MS, Hughes TP. 2007. Spatial distribution of juvenile and adult corals around Moorea (French Polynesia) : implications for population regulation. Bull. Mar. Sci. 80(2): 379-390.

Rogers CS, Fitz HIII, Gilnack M, Beets J, Hardin J. 2003. Scleractinian coral recruitment patternsat Salt River Submarine Canyon, St. Croix, U.S. Virgin Islands. Coral Reefs $3:$ 69-76.

Siringoringi MR, Palupi RD, Hadi TA. 2012. Biodiversitas karang batu (Scleractinia) di Perairan Kendari. Ilmu Kelautan 17 (1) : 23-30.

Vermeij MJA, Smith JE, Smith CM, Thurber RV, Sandin SA. 2009. Survival and settlement success of coral planulae : independent and synergistic effects of macroalgae and microbes. Oecologia 159 : 325-336. 